\title{
Possible impacts of the US EPA Notice of Proposed Rulemaking on the biofuels industry
}

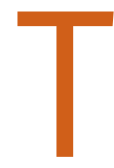

his Roundtable Discussion was held for members of the media to engage with industry experts and gain insight into the proposed (and, as this issue of Industrial Biotechnology went to press, yet-to-be-finalized) EPA Notice of Proposed Rulemaking that would set stringent greenhouse gas emission reduction targets for renewable fuels. At issue is the methodology employed by EPA, one largely based on assessment of emission effects related to indirect land-use changes for biofuels production, to determine the reduction target requirements for existing and new biofuels. (For context, see letter, p. 332, and Point of View article, p. 334). Industrial Biotechnology gratefully acknowledges the contributions of:

\section{KEITH COLE}

Director, Legislative and regulatory affairs, General Motors

\section{BRUCE DALE, PhD}

Professor, Chemical engineering and material science, Michigan State University and Great Lakes Bioenergy Research

BRIAN DAVISON, PhD

Chief scientist, Systems biology and biotechnology, Oak Ridge National Laboratory and Bioenergy Science Center

\section{BRENT ERICKSON}

Executive vice president, Industrial and Environmental Section, Biotechnology Industry Organization (BIO)

MICHAEL PARR

Senior manager, Government affairs, DuPont
BRENT ERICKSON: The purpose of this discussion is to provide some background information on the forthcoming release of a Notice of Proposed Rulemaking, or NOPR, by the United States Environmental Protection Agency (EPA) on enforcement of the renewable fuels standard, or RFS.

BIO has some concerns about the methodology the EPA has been employing to assess greenhouse gas emissions targets, but in general, we support the production of biofuel in the most sustainable way possible. BIO's member companies are involved in efforts to establish voluntary sustainable criteria for biofuels production and other types of production as well. And our member companies continually pursue greener, more efficient ways to produce biofuels and other consumer products. We believe that biofuels, biobased plastics, and other biotech-based products and processes can make a significant contribution towards solving the climate change problem.

I'd like to give some brief background history of this issue. Originally when Congress was considering the last energy bill that was passed, they had included language in the bill to allow the Department of Energy (DOE) to provide grants to study the issue of indirect land impacts of biofuels production on greenhouse gases. Then, rather at the last minute, the House inserted language that required EPA to complete a rulemaking to determine the appropriate model for estimating lifecycle GHG emissions and to finalize mandatory emission-reduction targets for renewable fuels to be considered eligible under the RFS. At the same time, the study language (that is, the provision of grants in support of studying indirect land impacts) was left in the legislation. It's an interesting legislative juxtaposition, directing federal agencies to study an issue while at the same time requiring them to set directives (here, in the form of emission targets) in their regulations. 
Our position is that we'd like for EPA to publish its methodology and let the scientific community and others comment on it without providing any data runs (or prematurely publicizing numerical estimates of the greenhouse gas reductions achieved by specific biofuels)-because, frankly, the science on indirect land use is very immature and the models are not sufficiently developed. I think this viewpoint is held both within the academic community and the private sector.

The Energy Independence and Security Act of 2007 amended the Clean Air Act by requiring that renewable fuels produced in new facilities whose construction commenced after the date of enactment achieve at least a 20 percent reduction in life cycle greenhouse gas emissions, compared to baseline life cycle greenhouse gas emissions. Baseline is defined as the average life cycle greenhouse gas emissions for gasoline or diesel sold or distributed as transportation fuel in 2005. Life cycle greenhouse gas emissions are defined as the aggregate quantity of greenhouse gas emissions, including direct emissions and significant indirect emissions (such as emissions for land use changes as determined by the EPA Administrator) related to the full fuel life-cycle. The EPA is generally charged with regulating greenhouse gas emissions as pollutants under the Clean Air Act. Now this mandate is being brought into the whole biofuel sector.

Biofuel producers represent the first industry to be explicitly regulated for greenhouse gas emissions, and this law could actually set a regulatory precedent for other industries. So it is imperative that these regulations be implemented transparently and with scientific rigor.

A group of academic experts and company CEOs, in a collectively drafted letter sent by BIO to EPA Administrator Stephen Johnson, expressed concerns about the inclusion of international land use changes and asked for a delay of the ruling. To quote the letter: "We strongly believe that the requirement to account for the ILUC [international land use change] in the legislation is premature, as there are no generally accepted methods for determining indirect land use change or for that matter, any indirect market-driven change. And there is no way to apply even current methods in any meaningful way to the choices a farmer makes. I'll forgo reading other parts of the letter. But needless to say, what indirect land use change is really about is agronomic systems and not actual biofuel plants, that is, the facilities for making biofuels.

Our panel today includes several notable speakers. Joining us are Bruce Dale from Michigan State University, Brian Davison from Oak Ridge National Laboratory, Keith Cole from General Motors, and Michael Parr from DuPont.

At this time, I'll turn to our first panelist, Dr. Bruce Dale, professor of chemical engineering in, and former chair of, the department of chemical engineering and materials science at Michigan State University and the Great Lakes Bioenergy Research Center. Dr. Dale appeared before EPA's scientific advisory board to give a presentation on sustainable paths to a biofuel-powered transportation sector and the role of innovations and invention. He recently co-authored a paper, Biofuels, Land Use Changes and Greenhouse Gas Emissions: Some Unexplored Variables, which has just been accepted for publication in Environmental Science and Technology. Bruce, I'll turn the dialogue over to you for a few remarks about your observations as someone who's studied this issue for some time.

BRUCE DALE, PhD: Those of us in the life cycle community are able to do life cycle analyses of what we call direct land use change. In other words, if you were to actually cut down a forest or plow up some conservation grassland, and that land were then converted to a cornfield for ethanol production-we know how to do the life cycle studies for that type of direct land use conversion. In other words, the conversion of an actual, identifiable piece of land, through which greenhouse gases could be released (through, for instance, the removal of the timber on that land and the resulting production of fuel by a facility which that land's biomass then supplies)-that's called direct land use change. And it's within the capability of the life cycle analysis community to assess that, in a fairly rigorous process.

The other issue can be a bit hard for people to get their heads around. What we're talking about today is indirect land use. The typical argument around greenhouse gas emissions, ethanol, and indirect land use says that if you divert, for example, some cornfields in the United States to make ethanol, then because you've taken that corn out of the marketplace, market forces will react to replace that corn or some other animal feed. Through a series of models (not just one, but actually several), this corn usage then becomes linked to the potential for some other party cutting down some Brazilian rain forest (this is the example that's commonly used) to make up for the feed that's no longer in the animal feed market.

That's indirect land use. It's about market forces. There's no direct relationship. In fact, you can't identify any particular actors within the chain. So it's not part of the specific supply chain for a biofuel facility. It's simply market forces that are acting in these models.

Here's an analogy that may help you understand. Since we have a General Motors representative on our panel, this may be appropriate. Let's say instead of biofuels, or in addition to biofuels, we start building a lot more electric vehicles. GM may then decide to source the nickel for the batteries for these electric vehicles from a particular mine such as one mine that actually exists, in Sudbury, Ontario, Canada, which is among the biggest nickel mines in the world. GM knows where the nickel comes from, and they buy that particular nickel. The supply chain is assessed for particular operational parameters of that mine and the environmental parameters of that mine. 
What the indirect-effects argument would say is that GM is not just responsible for the environmental effect of that Canadian mine. Instead, because GM increased the entire world demand for nickel, indirect-effects proponents would now assess GM with the hypothetical environmental impacts of a new nickel mine opened, for instance, in Africa. (Because the actual effects haven't been observed, they can only argue with the hypothetical.) And so, their argument goes, GM should be responsible for the direct effects as well as these indirect or market-driven effects.

In that sense, this approach adopts a very radical notion. But in addition, the life cycle community-people who do this analysis, such as myself-simply doesn't know how to handle these indirect or market-driven effects. So the EPA has been put in a very difficult position. They're charged with implementing a regulation, or providing background information on a regulation, for which we're not able to adequately assess the actual impacts. There are a lot of other technical issues that we may get to discuss later in this panel, but know that this is a complex situation. The science is just not able to support these types of policy regulations, when we simply don't yet know enough.

BRENT ERICKSON: Thank you, Bruce, for making that point about the uncertainty of current modeling capability.

Next we will hear from Dr. Brian Davison, chief scientist for systems biology and biotechnology at Oak Ridge National Laboratory and the Bioenergy Science Center. Dr. Davison recently served two years as director of Oak Ridge National Lab's Life Science Division. He is also an adjunct professor of chemical engineering at the University of Tennessee, Knoxville.

BRIAN DAVISON, PhD: I'm going to be talking more about where the science is, that is, this broader biofuels conversion area. I usually ask three big questions in discussions like today's. First, can we do it? This is the technology and cost question. Second, can we do enough of it to make an impact? And third, can we do it forever? This is the sustainability question, which is at the core of what this panel is focused on.

When we talk about technology, what we have implemented to date is what I would call "generation zero" technology-cornstarch conversion in the United States and the sugarcane in Brazil. Industry discussion around biofuels technology development and science generally acknowledges three types of technologies (that is, Generations One, Two, and Three) that are all at various stages in trying to get into the commercial market all once. Most of the later-stages technologies center on cellulosic-type conversion, with biorefineries using biomass both for fuel production and for powering the facilities. Relevant research in this area includes work that USDA and the DOE are doing, including at the Oak Ridge Bioenergy Science Center.
I think most of the panelists would agree that, as far as technology and cost are concerned, there are enough trends and indicators suggesting we will be able to get past the technology hurdles and drive production costs down to be market-competitive.

As for addressing total impact and magnitude: there have been a number of studies by Oak Ridge, USDA, and others that show we should in fact be able to achieve market-scale biofuels production - with certain reasonable assumptions. Some of this is referenced in the "Billion Ton" study [Editor's note: Biomass as Feedstock for a Bioenergy and Bioproducts Industry: The Technical Feasibility of a Billion-Ton Annual Supply, USDOE and USDA (April 2005)].

There is also a good amount of plant science research that's just really getting started in looking at the biomass crops themselves, such as switchgrass and woody crops. We might think of such plant species as being barely domesticated. When you consider how much improvement we've achieved in corn agriculture, in terms of being able to grow the crop better, it becomes clear we also can try to achieve similar improvements in the plant sciences for these dedicated crops.

At the same time that we are trying to make crops grow better, we should also try to grow them more sustainably and not make yield alone our driving force. We should focus on low inputs (that is, to minimize the use of synthetic chemicals, including fertilizers), low water use, and more-sustainable agronomic practices among our drivers for how we're trying to domesticate these plant species.

The University of Tennessee, for example, is investing in a pilot plant about 40 miles from my office, in a project focused on switchgrass; the university is working with DuPont and Danisco for conversion of the crop into pilot-scale production of ethanol (which I'm sure Michael Parr will speak about). They're growing the switchgrass locally, starting to adopt some of these sustainability-science measurements, and looking at issues related to the whole-life-cycle supply chain.

When we consider the question of whether we can produce biofuels indefinitely, we broach the sustainability issue. We begin to consider the use of dedicated biomass feedstocks, which will be perennials and require lower amounts of fertilizer, water, and other inputs. The scientific community would generally agree that these perennial dedicated crops will have better energy, water, and carbon balances. But even here, there is some debate about specifics. And the models that Bruce was describing earlier aren't strong enough to really say how much better these crops will be, only that they will be better.

So I would argue that we need to be careful about the regulations we set out, so as not to stifle an industry that is just beginning to get started, and where there isn't yet enough information based on actual past production to be able to make any of these judgments or measurements. 
BRENT ERICKSON: I think that we're pretty confident that the technology is available for production of second- and thirdgeneration biofuels. This rulemaking we're discussing today affects all biofuels. Traditional corn-based ethanol is being mandated to have a 20 percent improvement over gasoline in terms of greenhouse gases emissions - but cellulosic ethanol and other cellulosic biofuels must show a 60 percent improvement over gasoline.

So at a time when the economy is troubled, some of our concern relates to investment in new, second- and third-generation-biofuels technologies - because we have already begun commercialization of conventional ethanol, while we're just now poised to begin commercializing these next-generation fuels. Our concern with this rulemaking is that if EPA comes out with flawed models and numbers not based on sound science, it will send a very negative signal to the marketplace in terms of financing new production plants. Advanced biofuels, which have greater greenhouse gas benefits, are standing on the shoulders of corn ethanol, so to speak. We have to be concerned about the whole industry.

We'll hear next from Keith Cole from General Motors. Keith is GM's director of legislative and regulatory affairs, based in Washington, DC. He's had a long career as a lawyer, a Capitol Hill staffer, and as a policy maker and working with the administration. He's a keen expert on these issues and will give some perspective as to why General Motors is concerned about this rulemaking and why the comapny has invested in these advanced biofuels.

KEITH COLE: GM has invested in two advanced-biofuel companies, Coskata and Mascoma. Those are relatively small investments, which is one factor of our interest in this area. Our interest is in looking at how the fuel pool interacts with vehicles, with a forward look to a future where greenhouse gas emissions will likely be the "coin of the realm" and discussions will revolve around the life cycle emissions of one fuel versus another, one vehicle versus another. I'm personally involved in discussions on cap and trade, low carbon fuel standards, and other greenhouse gas performance standards.

We would like to get to a place where there are commonly accepted metrics for comparing different means of reducing greenhouse gases. For example, you can imagine a gasoline-powered car being compared to an ethanol-powered car, being compared a natural gas-powered car, being compared to a plug-in hybrid or electric vehicle. But how exactly do we compare these? How do we make trade-offs in our own investments to satisfy our own regulatory standards? And, importantly, how does the country assess which technologies are making the most progress or have the most potential for progress in the future?

Again, we would like to get to a place where we have commonly accepted approaches for comparing different fuel/vehicle combina- tions. We currently don't have such a means. With respect to the direct changes that Bruce was talking about, we do feel there are good methodologies for conducting life cycle analyses, and an EPA rule that resolves the previous discussions would be beneficial.

In regard to the indirect changes, there is a lot of ferment within the academic academic community and the assessment community over how best to do this. So while in the area of direct effects there may be disagreements over data (for example, how efficient one process is, what corn yields are, etcetera), there are no "big fights" over methodology; you may have some disagreements, but you don't have big ones.

In this new area of indirect impacts, we've not only got disagreements over data, but also over how to tackle it and how far to push out the causal relationships. So we'd like to see EPA raise those methodological issues and gather public comment on them, in a very transparent way, to get to a place where we have common metrics, that we might compare apples and oranges.

While we want to get to this point in the end, we also recognize this is an area in which there is a lot of heated debate. If you were to overlay the numbers that would be spit out by the formula EPA will come up with, you would see there's a lot of money at stake; by such analysis, a particular ethanol plant or biofuel plant could easily fall into or out of a particular category. We know that in the fuels community, there's a lot at stake. This proposed rulemaking is going to draw a lot of attention by the investment community. We've already seen some overheated rhetoric basically trashing biofuels. We would very much like to arrive at a definitive statement as to how we should compare total energy-efficiency and life cycle analyses for different fuels and vehicles.

We're looking forward to that process. We don't think in the upcoming proposed rule that EPA is really ready to issue a definitive comparative methodology, but we are very anxious that they come out with a proposed methodology and let the community comment on that, so that we might tease out these issues in the coming months.

BRENT ERICKSON: I think we all feel that premature publication of some type of inaccurate numerical land-use emission estimates from EPA could really erode the credibility of the whole modeling process and threaten the integrity of life cycle assessment and the future of advanced biofuels. It could also poison the dialogue that industry is having with various NGOs internationally.

We turn now to Michael Parr, senior manager of government affairs at DuPont. Michael manages federal government affairs activities related to science and technology, sustainability, environment, biobased materials, and energy and climate issues for DuPont and the global science community. 
MICHAEL PARR: I think at DuPont we bring a unique perspective to this conversation given that we broadly span the agricultural and biofuels value chain. We also comprise Pioneer Hybrid, a worldleading seller of seed corn. We invest a huge amount of money each year to continue to expand the yield, or productivity, of each acre of cornfield or soybean field. We develop technologies to continually increase production from each acre, which may both help to feed the world population and reduce pressure on additional land.

We are in the thick of developing some of these next-generation biofuels technologies that have been discussed. As Keith Cole noted, DuPont recently broke ground in Tennessee for a pilot plant to demonstrate our cellulosics conversion technology with two different feedstocks, corncobs and switchgrass. There is a lot of corncob biomass available in the world given the massive amounts of corn production. And what do you do with the cob, otherwise? Why not turn it into fuel? As for switchgrass, it provides the opportunity for another crop that has no connection to food demand but can produce large volumes of biofuels.

We are also partnering with our partner, BP, to develop a higherperformance biofuel, biobutanol, that we will demonstrate in the near future. We think that, as Keith mentioned, biofuels are going to be an important element of reducing the carbon intensity of transportation, which contributions a sizable portion of global greenhouse gas emissions and that may grow dramatically yet as developing nations become richer.

There's an urgent need to find a means of providing people in the world mobility with a much smaller carbon footprint. Cellulosic biofuels have the opportunity to be eight to nine times better than current hydrocarbon fuels for greenhouse gas emissions. So it's important that we accelerate rather than decelerate bringing these kinds of fuels to market.

We appreciate the ramifications of tropical deforestation, which represents about 20 percent of global carbon emissions today. We appreciate the effect of this phenomenon on people's attention to, and concern with, the possibility that somehow agriculture for biofuels through indirect effects might contribute to that carbon release.

This is, however, an area where there is a lot of theory and speculation and very little data or demonstrated causality. As EPA attempts to evaluate the potential magnitude of these kinds of effects through modeling, it's important that they take the time to get those models right.

As others have noted, there are standardized methods for evaluating direct land use. Organizations like the International Standards Organization and the American Society for Testing Materials have published standard methods that people can look to. To do its modeling of potential indirect effects from biofuels production, EPA essen- tially had to cobble together seven separate models, try to interlink them, and create data sets for all of them. They've done this in a technically robust, good-faith effort. But there really are no accepted models, and there are no standardized data sets. And so the levels of uncertainty in the modeling are quite profound. Changing even one small variable can result in a 20-times change in the resulting numbers that the model spits out.

We would very much like to see EPA hone that model to the point where it helps all of us really answer this question in a more refined and precise way. That way, we can know: Are greenhouse gas emissions from indirect land use really an issue? And if so, what is the proper way to develop biofuels to realize low-carbon benefits and avoid some of these potential indirect ramifications?

BRENT ERICKSON: This reminds me of the whole issue around externalities and electric utilities in some ways because they are so amorphous and hard to get your arms around. These discussions could also set a very interesting precedent for other industries.

STEVE POWER (Wall Street Journal): Keith, you talked about the fact that a lot of money is at stake. Could one or all of you comment on how much money might be involved, in this rulemaking? Is there any way you could try to quantify that? I know that's probably difficult, but it would give us a way to grasp this issue and see what's really at stake here. It sounds like this rulemaking is going to essentially determine which biofuels will be able to compete in a carbonconstrained regulatory environment under these mandates.

KEITH COLE: I'm not an economist; I'm an engineer and a lawyer, so I don't have any magic numbers for you. But look, the US renewable fuels standard is a 35-billion-gallon-a-year standard. Multiply that by whatever you think the price of gas will be, and that's the volume of the market - at least, the mandated market. Now, what we've seen in recent years is growth in the ethanol business above that. That's one data point you could look to, to get an idea of the potential market.

BRIAN DAVISON: In the US, we're currently at about a 7-billion to 8-billion-gallon-a-year capacity, mostly from cornstarch ethanol. The goal is to get to 35 billion. That gives you some sense of the magnitude of the growth of the industry that we're expecting from this - as well as the jobs and other economic factors that will come into play in the domestic markets and domestic industry.

MICHAEL PARR: Brian just pointed out a key factor. It's the potential investment that could be chilled, perhaps more than the steel on the ground that might be at risk. Several hundred millions of dollars have been spent in the US (probably approaching $\$ 1$ billion) on R\&D on next-generation biofuels, by a wide variety of entities. There are billions of dollars in capital poised to create this first generation of 
advanced-biofuels biorefineries. A typical-scale biorefinery is going to be a $\$ 200$ million or $\$ 300$ million investment - and it's going to take a bunch of such refineries to get 20-plus billion additional gallons of fuel into production.

The concern is not so much the accuracy of the numbers put forth by the EPA or others, or the decision that some fuels will be permitted and others not; instead, it's that the numbers play into a storyline that has been created by parties who have been opposing biofuels for their own reasons and lobbying the EPA and government against them, arguing that biofuels do not have good carbon balances. This erodes the public confidence in biofuels, on a highly inaccurate basis; it erodes the policy support for them. And that chills the investment climate. The venture capitalists start looking elsewhere to put their money. Such lines of thinking choke off the potential to bring these low-carbon biofuels to market at the pace that we need, if we're trying to avoid the kinds of locked-in carbon emissions that we will see if we continue to grow the use of petroleum transportation fuels.

STEVE POWER: You mentioned there are no generally accepted methods of tracing indirect land use changes back to meaningful data that would warrant domestically decreasing production of a given biofuel. Could you elaborate on the different ways one might assess indirect land use changes and some of the different ways proposed to do this?

BRUCE DALE: Again, if you're talking about a direct effect, that refers to something that's part of an individual biofuel facility supply chain. Indirect effects are market-driven, and so there are no responsible parties; there is, if you will, no "smoking gun".

If you increase demand for land, for instance, perhaps by producing ethanol from corn, then you are, by indirect-effect argument, responsible in a very amorphous and undefined way for something that might or might not occur. I guess I would point out also that there's actually very rich academic literature on the subject of land use change and the causes of it. In over 150 cases of land use that have actually been studied, agriculture itself (agriculture expansions, focused on simply planting more crops) is responsible for less than four percent of the observed pieces of land use change.

Indirect effects are more complex. They deal with scenarios like the following: say you have a government that, for its own reasons (such as for public-transportation infrastructure, that is, not for agricultural purposes) builds a road, a bridge, or a dam. So now you have a road. But farmers in that region now also have a way of getting crops to market that they may not have had before; and now they plow more. In this case, the agriculture wasn't the cause; the cause was, if you will, the road.

Or say you've harvested timber for whatever reason from a piece of land; now that land is cleared or the timber is no longer there.
Someone else might decide to take that land and convert it to agricultural plots. The causation effect in these cases is very diffuse and very hard to figure out. That's just one of the difficulties of applying an indirect land use idea to assessment of carbon emissions and biofuels production.

BRIAN DAVISON: If you put it in some other terms, people have pointed out as a counterargument to some of the statements we've made here that deforestation is an important and major concern. But deforestation has been occurring at significant rates that warranted monitoring long before this recent surge in interest in biofuels.

MICHAEL PARR: As Bruce Dale pointed out, it's important to note that the underlying assumption in indirect-effects arguments is that you change economic conditions by a practice; for example, if you have greater demand for corn grain to produce biofuels, that will raise the price of corn. But that assumes, of course, that the supply of corn didn't rise at an adequate rate to meet the new demand for biofuels supply. Also, it simply sets aside all other factors that affect agriculture: commodity prices, weather, global supply-and-demand dynamics, shipping constraints, trade imbalances. The indirect landuse change argument is too simplistic: More ethanol means more corn demand, therefore corn prices go up. Gee, that means someone somewhere is going to plant more corn. I'm going to "imagineer" where in the world that might happen and what kind of land that corn might get planted on. That's the kind of supply chain that's envisioned in these arguments.

But it's interesting to note that these kinds of indirect analyses should in no way be unique to biofuels. As demand in China and India increases dramatically for meat, which is occurring at a rapid rate, another hugely significant source of demand for grains is coming into play. Are we then going to "back-model" the greenhouse gas footprint-the indirect life cycle greenhouse gas impacts - of a plate of chicken sold in Beijing because that chicken ate soybeans?

Or, similarly, as the population continues to grow in America and as we then need to build more schools, more housing developments, new chain stores, are we going to debit pregnant families with the indirect life cycle greenhouse gas footprints because of their decision to have more children? Not likely. And so, to address biofuels in this way is to pick out a very, very narrow sector of the US economy and try out a whole new indirect regulatory concept that's never been applied elsewhere - and essentially make farmers and businesspersons in the US responsible for something over which they have absolutely no control, that may or may not actually happen elsewhere in the world but that a theoretical model merely suggests might occur.

STEVEN COOK (BNA Daily Environment Report): Even if the way to measure these indirect effects is untested, or maybe, at this point, even 
nonexistent, isn't it at least possible that there are significant indirect effects and that they should be modeled or measured in some way? Shouldn't work be done to develop accurate models for these things?

BRIAN DAVISON: All of us would agree that that's the major point. Better models need to be developed and tested that result in some data of causality to show the models actually work. So, yes, absolutely we should be considering these indirect effects.

MICHAEL PARR: To be clear, we're not suggesting that EPA shouldn't do this modeling. In fact, we think they've been doing yeoman's work, along with USDA and DOE, to try to improve their modeling. What we're suggesting is that EPA use the power of the regulatory public-comment process to gather a broader array of input and assistance in developing their models. And when the model is developed to such a point that EPA can have reasonable confidence in it as a regulatory tool, then by all means use it. That's the value of this current rulemaking process, in our view - to help them gather that kind of input.

BRENT ERICKSON: I want to add that, in some ways, Congress has in a sense put EPA in a box; because they passed legislation that instructed federal departments to invest into studies of greenhouse gas emissions, even when Congress acknowledged that the models weren't well-developed. They've boxed the agencies in, in a way.

STEVEN COOK: Do you think that EPA can develop models that are reasonable by next year, when they're due to finalize this?

BRENT ERICKSON: The Department of Energy has a contract with Purdue University's Global Trade Analysis Project to develop computable general equilibrium models (to assess the spill-over effects of greenhouse gases abatement policies. And there are some other models under development, well under way, that could likely be used within the next year or two.

COOK: Is the EPA rulemaking eminent?

BRENT ERICKSON: The administrative deadline was October 31. The EPA was trying to get all the new rules in by that date. From what we can gather from different sources, the Notice of Proposed Rulemaking is close to being finalized.

JENNY MANDEL (Greenwire): With the rulemaking due, does BIO anticipate litigating if the group isn't happy with the science behind the indirect land use change verbiage? Also, what kind of science needs to be done to achieve the certainty that you are calling for on this issue?

BRENT ERICKSON: We haven't had any discussions about, or consideration of, litigation.

BRUCE DALE: Regarding the science that would need to be done, at a minimum, you would have to test not just one model but multiple models to show that the findings were robust. My friend, Dr.
Lee Lynd (of Dartmouth College) and I looked at the analysis done by the Searchinger paper [Editor's reminder: Use of US croplands for biofuels increases greenhouse gases through emissions from land-use change. Timothy Searchinger et al. Science 319(5867), 1238-1240 (29 February 2008)]. If you just look at the variables that could be tested in Searchinger's analysis, there are well over 500 different variables and combinations of them; the Searchinger analysis only examined a handful of those. So I'm not as optimistic as Brent that we can arrive at an answer within a year or two. Here's the reason:

The Searchinger analysis assumed that a forest would essentially be burned down and that no productive use be made of the existing biomass on that land. As Lee and I considered, what happens if you decide ahead of time that you would first harvest that material for timber or for pulp and paper? That timber pulp and paper would be used in the economy, which would offset greenhouse gases of some other product that required energy or greenhouse gases to produce.

So we looked at that analysis. We looked at the effect of how one might manage the change in the land after the conversion-because you don't stop managing land once it's converted. And we looked at, for example, factors such as cover crops and no-till agriculture in corn. We found that if you bring into the analysis what you can do with the timber, and combine that usefulness with ways of better managing the land, the so-called carbon debt can be erased-gone. It wouldn't exist any more.

That's how wide a swing in the outcome can result, just by a fairly simple change in one's assumptions. And there is a huge set of assumptions that have to be tested. It might end up being lifetime employment for modelers - quite literally - because there's so much to be done here.

Myself, I have a very hard time believing that we can ever come up with really robust models for determining indirect use effects. The world is just too complicated, and we don't understand it all. Indirect land-use analyses are fundamentally economic models. How much confidence, honestly, do we have in economic models? The economic crises of this past year, and especially the last few months, ought to tell us something about the reliability of current economic models.

So while the analysis has to go forward, we have to study this process of effects from indirect use. Again, I'm personally not at all optimistic that we can come up with results that will be scientifically robust, because we're dealing with the whole economic system of the whole world plus all the ways we use land. It's extremely complicated.

JENNY MANDEL: With respect to the comment that Michael Parr just made about not being against the development of research that can be used to model this, are you saying that there's really no way to assess greenhouse gas emissions and biofuels production in a rigorous way? 
BRUCE DALE: I think we have to understand what the trade-offs are. I'm a researcher, so I'm not going to argue against research. I'm trying only to explain the immense job that we have laid out for ourselves in doing this particular kind of research. There are hundreds and hundreds of different variables - numerous assumptions. And, again, we're dealing literally with the entire global economic system: the way we use land and the whole world of use and production.

Again, I'll give you a very specific example. The models that were used to do the estimate by Searchinger did not account for land that's been abandoned or is unused worldwide. There are roughly one billion acres of under-used land worldwide that at least are conceivably available for biofuel production; that land was not included in Searchinger's analysis. The database they used only includes land that's currently being operated or farmed. This is an example of the kind of improvement of a model that we would have to do, because, certainly, some of that currently unused land will get used for biofuel production. And the model that was tested didn't even account for that kind of land being in existence. This gives a further idea of the difficulty and the complexity of what we're dealing with here.

MICHAEL PARR: Another fine example is the assumption that to create the additional grains needed for ethanol production, you'd have to convert non-agriculture lands. The simple fact of the matter is that, while corn, soybean, and other crop yields in the US are quite high (they've increased year on year on year, for the last 60-70 years and will continue to grow at an accelerated pace for the next 20 years), other parts of the world lag dramatically. Simply by applying current US levels of agricultural productivity to, say, sub-Saharan Africa, you could have five times the current African output of grain without any new lands there coming into agricultural use; that would just be with existing acreage. You could essentially create agricultural production double the US total simply by having higher rates of yield in other parts of the world. There are numerous different moving pieces in the global agricultural economy. The life cycle work that's been done to date in studies like the Searchinger analysis, has essentially only cherry picked a very narrow set of assumptions, that can often be viewed as relatively unfavorable, to arrive at a somewhat exaggerated result.

BRIAN DAVISON: I would add another aspect of the challenge here, namely, the need we have for the types of data sets that validate how biofuels really do affect the variables we're studying. The issues are broad and challenging, as you may gather: we're considering international and domestic land-use issues. Since we're talking about growing crops, one can imagine that, if we were to collect one data point a year for each acre of land that's used, it would take at least a couple of years to gain enough data that we could really begin to validate the projections that would come out of initial models.
DAWN REEVES (Inside EPA): I know the rule is delayed and that you expect it out at some point in the near future. Do you have any expectations for what EPA is going to do? I know there have been many letters back and forth, and meetings with EPA and other agencies. What would be your best guess as to their final decision?

BRENT ERICKSON: I don't think we have enough information to make an educated guess. The only thing that we've heard and deduced, through our meetings with EPA and from third parties, is that the model they're using - well, one EPA person called it "Searchinger Lite" - basically a cobbled-together model using parts of several different models. And that's part of our concern.

DAWN REEVES: Given that the current energy legislation requires EPA to come up with an analysis model, is what you're requesting them to do (in terms of putting out the model without having run it) conceivably part of the law?

BRENT ERICKSON: This is only a Notice of Proposed Rulemaking. What we're asking EPA to do is to publish its methodology so that the scientific community can critique it, and we're asking them to use the public-comment period so that others might suggest improvements and point out flaws in the model, enabling EPA to go back and improve the models it is using.

DAWN REEVES: Could EPA do this within the time frame that the statute gives it to finalize the rule?

BRENT ERICKSON: I think EPA does have flexibility under the law to conclude that there is either sufficient or insufficient scientific modeling ability.

MICHAEL PARR: Let me provide a little more texture to that. The entire legislative direction on this is a parenthetical phrase in the definition of life cycle greenhouse gas modeling that mandates the inclusion of significant indirect effects, including indirect land use effects.

There is no legislative history of such a requirement. Typically, when Congress makes a decision to open up a whole new area of regulation, there are multiple hearings; there's a lot of discussion; there's testimony about the nuances of what the regulations might mean. The Notice of Proposed Rulemaking about indirect effects and greenhouse gas emissions came over the transom at the eleventh hour. The Congressional Research Service took a look at the legislative history of such a decision, and there basically is none. There is a fair bit of parsing that must be done to figure out just what exactly Congress was really wanting EPA to achieve.

But if you look at the language of the proposed rulemaking, it says "significant indirect effects as can be determined by the Administrator". What we're suggesting is that you have no way of knowing whether these indirect effects are significant until you can get adequate accuracy and precision in the model: The model may 
put out big numbers, but you'd have no idea if those were significant. You'd just know they're big.

We're of the view that the law does not require EPA to publish the numbers. The law requires the agency to try to figure out if there are significant indirect effects. The only way to properly do that is with an adequate model.

BRENT ERICKSON: We have the Congressional Research Service report on the legislative history. Within a document that was just released, there is a record of a portion of a hearing where Congressman Nick Lampson (22 $2^{\text {nd }}$ District of Texas) said the following:

"The committee also believes we need a better understanding of the emission and energy balance associated with the life cycle of biofuels from feedstock production to final use. If we are to reduce carbon emissions associated with fuel use, we need to understand the emissions associated with biofuels as well as others.

"Because biofuels are produced from feedstocks that first absorb carbon from the atmosphere, it may be possible to produce, process, and utilize biofuels in a manner that substantially reduces our current level of greenhouse gas emissions. Better life cycle models that track emissions throughout the production process and fuel use cycle can help us in the design of systems to minimize carbon emissions. The committee intends that DOE support improvements to the current modeling capabilities in this area as well as supporting research to develop new modeling and analytical techniques." So I would refer individuals to that Congressional Research Service report. [Editor's note: The CRS is available at http://biofuelsandclimate.files. wordpress.com/2008/12/salazar-lifecycle-ghg.pdf)

MIKE MILLIKIN (Green Car Congress): Do you know if there is any coordination between EPA and what it's doing, and the California Air Resources Board and its efforts to include indirect land use in that state's low-carbon fuel standard? Or to put it another way, what's the potential that we end up with two separate regulatory methodologies for assessing indirect land use?

BRENT ERICKSON: I have no direct knowledge that EPA is coordinating with California. From that I could conclude that we could end up with two different regulatory regimes. But I don't know: I'll turn to the other panelists, if they have any other information on this.

MICHAEL PARR: The two are certainly aware of what the other is doing. I don't think there is any significant level of coordination. And the fact that they are both building their own models and potentially coming out with very different results is, I think, symptomatic of the fact that there isn't a standardized approach. We run the risk of creating a rather ad hoc regulatory process.

I would note that there's an organization called the Roundtable on Sustainable Biofuels, a multi-stakeholder, Wiki-based type of forum for developing sustainability standards for biofuels. It's organized and run by World Wildlife Federation in Switzerland, and their process is very interesting. They've just put out what they call their "Zero Version" of their principles for sustainable biofuels development ("zero" being the first version). They looked at this issue of indirect land use. As you might imagine, the Roundtable on Sustainable Biofuels is basically a green organization, with a lot of green NGOs involved in developing these standards. They came to the conclusion that they could not pass judgment about their principles because there were no standardized methods available.

What they advocated was that we collectively spend the next year trying to develop globally standardized methods to evaluate these kinds of potential impacts; in the meantime, people should use sensible best practices in how they produce their biofuels to avoid the potential for negative indirect impacts. Again, what Congress has done essentially is ask EPA to drive out beyond its headlights on this - and thus the concern this Notice of Proposed Rulemaking is raising.

STEVE POWER (Wall Street Journal): I have two questions. To make sure I understand: Do all the participants in this call support the idea of measuring the emissions created from indirect land use changes and eventually including that data in whatever regulations do result for measurement of carbon and the global warming footprint of biofuels?

Second, would you elaborate on how a carbon debt can sometimes be offset by uses of the timber after a forest has been burned down? I didn't quite follow that concept.

BRENT ERICKSON: What we're faced with is what's in the law now; we're trying to make that work as best we can. I would point out that when we talk about the carbon debt related to biofuels, the alternative is to continue to burn fossil fuels or oil-an alternative that creates a carbon debt that can never be repaid. It is like comparing apples to oranges.

BRUCE DALE: This is complicated, and I do appreciate how difficult it is to wrap our heads around some of this. But the point about indirect land use change is that it cannot be measured. It can only be modeled; you can only have mathematical constructs that try to tell you what that effect is.

To measure direct land effects, I can actually go out to the piece of land that was converted for biofuel production, that is now feeding a specific biofuels facility, and I can reasonably quantify what actually happened to that land. With indirect land effects, this is impossible to do-because for indirect land effects, the system in question is the whole world, or at least all the agricultural land in the whole world. And it's not possible to identify any specific piece of land that actu- 
ally contributed to the change. So that leads to the answer to the second question you had.

The EPA model inherently depends on two things. And again, the EPA has not used just a single model but multiple models that are linked together. But models depend on data - in other words, the numbers that you put into them. And they also depend on the assumptions that you make about how the world works and what goes into a model and what doesn't.

When Mr. Searchinger did the analysis of indirect land use, he assumed that the forest was simply burned down and that no productive use was made of that particular plant material, that is, of the standing timber. However, a very plausible alternate scenario could have seen that land harvested for timber that then went to produce products; or maybe the timber had already been harvested and used to make pulp and paper. When we did repeated Searchinger's analysis method and checked on the results of this alternative assumption, we found that if you harvest the timber and make furniture out of it, or if you harvest the timber and make paper out of it, those products would replace paper or timber in the economy, in the market, and their production would otherwise have been associated with its own greenhouse gas cost.

There are certain greenhouse gas consequences, for example, of growing timber in the southeastern US; .if you grow timber in the southeastern US, in essence, you get a credit. All this is accounting. It's basically a very detailed and large accounting system. So if, instead of just burning the timber down and releasing the carbon dioxide directly into the atmosphere, you took that timber and made something useful out of it, you would receive a credit for producing those products, since they would replace other products (that would have their own greenhouse gas emission costs) in the market that now you didn't have to make. That's what that assumption is.

STEVE POWER: I thought the point was that, when Searchinger did his analysis, he assumed that when the rainforest is burned down, no productive use is made of what's left over.

BRUCE DALE: Essentially that's right. In fact, the assumption was that no productive use is made of the timber that was occupying the land. He assumed, for example, that the timber was just simply burned down or chopped and left to rot, which gives you the same result.

STEVE POWER: So conceivably if the timber that had been chopped down or burned were otherwise somehow used to make paper or other wood products, those would then replace paper or wood products created elsewhere else in the economy, thus avoiding the emissions of greenhouse gases that would have been created in those processes?

BRUCE DALE: That's right. And so, if you start exploring those assumptions, you see you get a much wider range of outcomes than were given in the Searchinger analysis.

This Journalists' Roundtable is an edited transcript of a teleconference discussion organized by BIO's Industrial \& Environmental Section. For more information, contact Paul Winters. Email: pwinters@bio.org. Web: www.bio.org. 
October 21, 2008

The Honorable Stephen L. Johnson

Administrator

United States Environmental Protection Agency

1200 Pennsylvania Ave. NW

Washington, DC 20460

Dear Administrator Johnson:

We are writing concerning the EPA's imminent rulemaking in response to the Renewable Fuel Standard passed in the Energy Independence and Security Act of 2007. In that legislation, the EPA was called on to determine the GHG lifecycle emissions reductions due to production of various biofuels. The EPA was directed to account for "significant indirect emissions such as significant emissions from land use changes" (ILUC) in their assessment.

We strongly believe that a requirement to account for ILUC in the legislation was premature, as there are no generally accepted methods for determining indirect land use change, or for that matter, any indirect (market-driven) change, and there is no way to apply even current methods in any meaningful way to the choices a farmer makes. We are not aware of a single published paper in the lifecycle literature using indirect effects, and the International Standards Organization (ISO) has published no standards for analyzing indirect (market-driven) effects. In short, what the legislation requires is currently impossible.

We believe that the GHG lifecycle benefits of $2^{\text {nd }}$ generation biofuels, in particular, are very positive. However, if flawed assumptions and methods are used to determine GHG lifecycle emissions reduction, then the GHG emissions benefits of biofuels produced from perennial grasses, such as switchgrass and Miscanthus, may be underestimated substantially.

Of particular concern is that the EPA appears to be relying heavily on the February 2008 paper concerning potential land use change impacts authored by Searchinger et al (Science, 319, 1238-40, 2008). We believe this would be a grave error. The Searchinger paper started an important policy discussion, but it is certainly not the last word on the issue. This paper presented a "gedanken" experiment about potential ILUC impacts under a narrowly cast set of assumptions. The authors started with an assumption that any acre taken out of food production in the US would lead to an increase in global agricultural acreage, leading to conversion of native acres to food production acres. In the model Searchinger et al used, there is little elasticity in food demand, land productivity, land availability, etc.

For example, the authors claim that "[t]he diversion [of land from food to biofuel production] triggers higher crop prices, and farmers around the world respond by clearing more forest and grassland to replace crops for feed and food." While there can be pressure to free up previously "native" lands, a large number of underutilized acres are available globally, and whose conversion to either food of biofuel production would not necessarily lead to any conversion of "native" lands. Two hundred million cattle are grazing on 500 million acres of pasture land in Brazil; experts project that 150 million acres could be made available for biofuels, with increased intensification of meat production on the remaining 350 million acres, without affecting food supple or "native" land conversion. 
Furthermore, the Searchinger paper took the rates of land use change occurring worldwide in the 1990s as a basis for land use change a decade from now, around 2015. There is no basis for such an assumption. These authors also assumed that all of the historical land use change was driven by agricultural expansion. This is a naïve and uninformed assumption. Of 152 cases of land use change studied worldwide, only 4\% could be associated with agricultural expansion alone. The cluster of factors that drive land use change is much more complex than the single factor agricultural expansion driver assumed by Searchinger et al.

Additional research is being done on ILUC utilizing different assumptions than the Searchinger paper and very different results are emerging. For example, the Searchinger paper assumed that the worst (most prone to release soil carbon) tillage practices were used on converted land. However, if current average tillage practices, or the emerging best practices, are used instead, much shorter "payback" periods result. In summary, the science and appropriate methodologies for ILUC analysis are just beginning to be done. EPA should delay rulemaking until the science is ready.

In the Renewable Fuel Standard, Congress called for increasingly large amounts of biomass for biofuels to come from low-carbon biomass sources, such as switchgrass and Miscanthus, from 2015 onward, to meet the combined targets on energy security and climate change mitigation. Switchgrass and Miscanthus are perennial crops, with low nutrient requirements, and they also sequester carbon into soil through their extensive root development. Since these products can also be produced on lands with soil types that are not suitable for high-yield production of annual food crops, their production on alternative lands are likely to contribute strongly to both energy security and mitigation of climate change. It would be very unfortunate if a rush to judgment by the EPA would cast unwarranted doubt on the value of these low-carbon, 2nd generation biofuels.

For these reasons, the undersigned urge to delay this aspect of the rulemaking that is currently planned for October $31^{\text {st }}$, and to utilize new general models for agricultural land, economics, and trade that will give a more realistic assessment of potential adverse effects of indirect land use change.

Thank you for considering this recommendation.

Sincerely,

Bruce Dale, PhD

Distinguished Professor, Michigan State University

Kenneth More, $\mathrm{PhD}$

Professor of Agronomy, Iowa State University

David Bransby, PhD

Professor of Agronomy, Auburn University

Robert Brown, PhD

Anson Marston Distinguished Professor of Engineering, Iowa State University
Brian H. Davison, PhD

BioEnergy Science Center, and Chief Scientist, Systems Biology and Biotechnology

Oak Ridge National Laboratory

Neal Gutterson, $\mathrm{PhD}$

President \& CEO, Mendel

Richard Hamilton, $\mathrm{PhD}$

President and CEO, Ceres 